\title{
ARQUITECTO, NO INGENIERO: REFORMAS DEL ACADÉMICO MELCHOR CANO EN LAS MURALLAS DE SEVILLA
}

\author{
ARCHITECT, NOT ENGINEER: REFORMS BY THE \\ ACADEMIC MELCHOR CANO IN THE WALLS \\ OF SEVILLE
}

\author{
Manuel Gámez Casado \\ Universidad de Sevilla. España \\ mgamez@us.es
}

\begin{abstract}
El presente artículo parte del análisis de las modificaciones que el arquitecto Melchor Cano realizó en el sector sur de la muralla de Sevilla. Si bien, más allá de tal estudio, su labor se debe encuadrar en el debate surgido en el primer tercio del siglo XIX entre ingenieros y arquitectos, pues ambas profesiones se alejaban tanto en lo formativo como en lo institucional. Por ello, en las líneas que siguen se atenderán a los distintos planteamientos que apoyaban o no los trabajos de los arquitectos en los edificios defensivos, resultando un nuevo estudio sobre un académico de limitada producción pero de alto sentido teórico.

Palabras claves: arquitectura; ingeniería; murallas; Sevilla; siglo XIX.
\end{abstract}

This paper analyzes the modifications that the architect Melchor Cano made in the walls of Seville. His work is within the debate between engineers and architects in the $19^{\text {th }}$ century. In the lines that follow will be studied the different approaches that supported or not the works of the architects in the fortified heritage. This is a new study on a scholar of limited production but with a high theoretical sense.

Keywords: architecture; engineering; walls; Seville; $19^{\text {th }}$ century.

Es propio de la arquitectura defensiva de las ciudades acumular en sus muros las consecuencias del paso del tiempo, materializado en continuas remodelaciones, modificaciones de sus trazados y restituciones de los elementos maltratados o caducos. Esta continua actualización del perímetro fortificado, debida en muchos casos a los ingenieros militares, obedece a su función protectora frente a los asedios, saqueos y posibles ocupaciones de las ciudades y del territorio que 
defendían. Por ello, las más importantes plazas siempre han procurado el mejor sistema defensivo, pues de su correcto funcionamiento dependían la seguridad de la población, de su comercio, de la economía de sus gobiernos y, en general, de la vida ciudadana. Sevilla, como enclave estratégico que fue desde época antigua, contó con imponentes murallas, cuyo primer trazado romano fue modificado en tiempos musulmanes, especialmente por almorávides y almohades, hasta convertirse en reflejo de las conquistas y reconquistas que protagonizaron las distintas culturas a lo largo de la historia de la ciudad ${ }^{1}$. Entre estos hechos, figuran las acciones de Julio César, Yusuf I y, sobre todo, Fernando III el Santo, cuyo cronista, según recoge Peraza, ensalzaba a Sevilla como la ciudad mejor cercada, señalando que "sus muros eran altos, anchos y fuertes en demasía", por más que el monarca castellano interviniese poco en ellas ${ }^{2}$.

A pesar de su importancia, la valoración de las murallas hispalenses no ha sido positiva siempre, pues pasado el tiempo llegaron a ser consideradas como inservibles, molestas, viejas y un estorbo para el desarrollo urbano ${ }^{3}$. Tales calificativos obedecían al ideal urbanístico del siglo XIX, cuando distintas corrientes europeas proponían la apertura de grandes avenidas que potenciasen un mayor tránsito de personas, carros y mercancías. Se consideraba que con la mejora del transporte se facilitaría la expansión económica, pues era imprescindible para la producción en masa a la que obligaba la nueva industrialización decimonónica ${ }^{4}$. Para conseguir tal propósito, la ciudad no podía estar constreñida por un muro. Además, su destrucción reduciría el riesgo de epidemias al facilitar la entrada

${ }^{1}$ Hasta mediados del siglo XX, la historiografía había considerado a las murallas hispalenses como una fábrica romana, obviando las distintas modificaciones a las que posteriormente fueron sometidas. Dichos estudios fueron recogidos por CARRIAZO, Juan de Mata: "Las murallas de Sevilla", Archivo Hispalense, 448-449, 1951, pp. 9-39. De las posibles cronologías que se han establecido para la muralla da cuenta JIMÉNEZ MAQUEDA, Daniel: "Algunas precisiones cronológicas acerca de las murallas de Sevilla", Laboratorio de Arte, 9, 1996, pp. 11-22; y del mismo autor "Las murallas de Sevilla: una aproximación historiográfica", Archivo Hispalense, 248, 1998, pp. 9-32.

${ }^{2}$ PERAZA, Luis: Historia de Sevilla. Sevilla, 1997, pp. 355-356.

3 Así lo recoge TORRES BALBÁS, Leopoldo: "Las murallas que caen”, Arquitectura, 34, 1922, p. 69.

${ }^{4}$ DE SETA, Cesare: "Las murallas, símbolo de la ciudad", en DE SETA, Cesare y LE GOFF, Jacques: La ciudad y las murallas. Madrid, 1991, pp. 63-64. El pensamiento expuesto generó la apertura de grandes avenidas radiales en París entre 1853 y 1869. En Viena, se demolieron las murallas conservándose únicamente pequeños restos a nivel arqueológico, mientras que en La Habana fueron destruidas casi en su totalidad en 1873. Diferente fue el caso de ciudades como Bérgamo, León, Lugo o Ávila, pues se conservaron sus murallas en contra de los ideales urbanísticos propios del ochocientos. Al respecto, véase BASSEGODA NONELL, Juan: "Aprovechamiento de las fortificaciones en los ensanches de poblaciones", Castillos de España, 121-122, 2001, pp. 35-40. 
de aire limpio a sus calles. Asimismo, en el debate sobre el futuro de las murallas existía un matiz simbólico, pues como se comprueba en el caso sevillano, fueron juzgadas como prescindibles, producto de otra época y sin valor artístico ${ }^{5}$. A todo ello se le unieron los estragos generados en la cerca hispalense por la invasión francesa y las guerras carlistas, cuyos ataques generaron unos gastos de reparación del recinto amurallado inasumibles por las arcas municipales ${ }^{6}$.

Las razones expuestas sirvieron al Ayuntamiento de Sevilla para proponer el derribo de las murallas y puertas. Así, hace más de un siglo que Gestoso recogía las propuestas de Francisco Pagés del Corro, teniente de alcalde de la ciudad, sobre la conveniencia de derribar la puerta de Jerez, "puesto que ya habían comenzado a demoler las murallas por la de la Barqueta"7. Dicho propósito, aprobado por el cabildo en septiembre de 1864, se enmarca en un periodo nefasto para las murallas hispalenses, cuya destrucción respondió a las nuevas ideas urbanísticas impuestas por los arquitectos municipales. Entre estos, José de la Coba y Juan Talavera apoyaron la desaparición del recinto murario por considerarlo un obstáculo, aconsejando su restitución por otros edificios que embelleciesen el perímetro urbano. Otras voces reclamaron la paralización del derribo, siendo ejemplo de ello la Academia de Bellas Artes de San Fernando de Madrid, institución que abogó por frenar el espíritu destructor impuesto por el Ayuntamiento hispalense ${ }^{8}$. Sin embargo, el eco de estas protestas fue tan limitado que incluso se inició el derribo de las puertas, pues a pesar de algunos intentos por parte de ciertos intelectuales por conservar las que tuviesen valor artístico, conforme al modelo parisino, la mayoría fueron demolidas para abrir algunas de las avenidas y plazas que hoy conforman el callejero sevillano ${ }^{9}$. Aprobadas dichas destrucciones en 1830 por el asistente José Manuel de Arjona, el primer sector derribado fue

5 MORALES, Alfredo J.: "Un episodio en el derribo de las murallas de Sevilla", Laboratorio de Arte, 25, 2013, pp. 689-700.

${ }^{6}$ MORALES, Alfredo J.: "Las murallas de Sevilla", en Congreso Internacional Ciudades Amuralladas. Pamplona, 2005, p. 157.

7 GESTOSO Y PÉREZ, José: Sevilla monumental y artística. T. I. Sevilla, 1889, pp. 18-19, nota 2. En fechas recientes ha sido fijado el discurrir del lienzo de muralla correspondiente al sector de la Barqueta, que han estudiado RAMÍREZ REINA, Francisco Óscar y GARCÍA TAPIAL, José: "Identificación del trazado de la muralla de Sevilla en el sector de la puerta de la Barqueta", Archivo Hispalense, 233, 1993, pp. 155-166.

8 VÁZQUEZ CIENFUEGOS, Sigfrido y LINARES GÓMEZ DEL PULGAR, Mercedes: "El derribo de las murallas de Sevilla: aspectos militares y urbanísticos", en AA.VV.: La era isabelina y la revolución (1848-1875). Actas de las XIII Jornadas Nacionales de Historia Militar. Sevilla, 2006, pp. 1513-1517.

${ }^{9}$ Es conveniente recordar que algunas de las puertas fueron diseñadas por arquitectos de renombre, siendo especialmente relevante las debidas a Hernán Ruiz el Joven en el caso de las de Carmona, Carne o Real. MORALES, Alfredo J.: Hernán Ruiz el Joven. Madrid, 1996, p. 117. 
la coracha que unía la Torre del Oro con la propia muralla, pues ello permitiría abrir una nueva avenida paralela al curso del río ${ }^{10}$. La demolición continuó por el sector oeste de la ciudad hasta la puerta de San Juan, justificándose su desaparición por la necesidad de ensanchar los márgenes del Guadalquivir para instalar las vías del ferrocarril ${ }^{11}$. Finalmente, de esta oleada destructora se salvaron los lienzos que enlazan las puertas de la Macarena y de Córdoba, después de que el Ayuntamiento reconociese su valor histórico, pues serviría para el estudio de las antiguas defensas militares de la ciudad ${ }^{12}$.

Como se ha señalado, desde las primeras décadas del siglo XIX, las murallas no gozaban ni de la utilidad, ni del reconocimiento que antaño habían tenido, siendo prueba de ello el episodio que se recoge en las líneas que siguen. Al respecto, se presenta un estudio centrado en el entorno de la Puerta de Jerez, relativo a los trabajos que el arquitecto académico Melchor Cano acometió tanto en el lienzo de muralla del sector sur de la ciudad, como en la coracha que unía el Real Alcázar con la Torre del Oro. Su labor partía de unos reconocimientos previos en los que demostraba no solo la ruina de los muros, sino también su escasa utilidad al perder cualquier uso militar, aunque servían para contener las aguas durante las crecidas del río ${ }^{13}$. Además, el análisis permitirá reflexionar sobre la visión que un arquitecto de formación académica podía tener sobre una muralla medieval, que condicionaba no solo la estrategia defensiva de la ciudad, sino

${ }^{10}$ Para conocer la política del asistente de Sevilla José Manuel de Arjona, véase BRAOJOS GARRIDO, Alfonso: D. José Manuel de Arjona, asistente de Sevilla, 18251833. Sevilla, 1976.

${ }^{11}$ RAMÍREZ REINA, Francisco Óscar: "Las murallas de la ciudad", en NAVARRETE PRIETO, Benito y FERNÁNDEZ GÓMEZ, Marcos (eds.): Patrimonium Hispalense. Historia y Patrimonio del Ayuntamiento de Sevilla. T. I. Sevilla, 2014, pp. 151-152. Es necesario saber que el Ayuntamiento de Sevilla le encargó al arquitecto Balbino Marrón la reordenación de este sector, donde la antigua muralla se sustituyó por un muro que contuviese las crecidas del agua, además de separar las vías del ferrocarril del entorno urbano. GONZÁLEZ CORDÓN, Antonio: Vivienda y ciudad. Sevilla 1849-1929. Sevilla, 1985, pp. 31-49.

${ }^{12}$ MORALES, Alfredo J.: "Un episodio en el derribo...,", op. cit., p. 694. Además de los restos comentados, también se conservan otros en el entorno de los jardines del Valle y en la zona sur de la ciudad. Al respecto, consúltese GARCÍA TAPIAL Y LEÓN, José y CABEZA MÉNDEZ, José María: "Restauración de las murallas de la Macarena", Aparejadores, 20, 1986, pp. 6-17; GARCÍA TAPIAL Y LEÓN, José y CABEZA MÉNDEZ, José María: "Restauración de las murallas del jardín del Valle", Aparejadores, 26, 1988, pp. 26-32; y CAMPOS CARRASCO, Juan Manuel: "Excavaciones en la muralla medieval de Sevilla: el lienzo de la Macarena”, Archivo Hispalense, 218, 1988, pp. 187-206.

${ }_{13}$ Sobre la reurbanización del entorno de la Puerta de Jerez existe un estudio que analiza el derribo de la muralla en ese sector, pero que solo menciona de forma sucinta el reconocimiento aquí tratado. La monografía se debe a ESPIAU EIZAGUIRRE, Mercedes: $L a$ Casa de la Moneda de Sevilla y su entorno. Historia y morfología. Sevilla, 1991, pp. 193-194. 
también su crecimiento urbanístico. Asimismo, la reforma de Cano ejemplifica el conflicto existente durante el siglo XIX en España entre arquitectos e ingenieros, pues a estos últimos se les encomendaron las defensas de las plazas y el diseño de sus infraestructuras una vez que se produjo la separación entre arquitectura e ingeniería tanto en la formación como en la práctica profesional ${ }^{14}$.

Ciertamente, el fragmento de muralla que corría entre las puertas de Jerez y San Fernando sufrió una completa reforma a mediados del siglo XVIII tras la finalización de la Real Fábrica de Tabacos y de las viviendas que se edificaron enfrente por el ingeniero Sebastián van der Borcht, lo que permitió replantear un espacio que hasta entonces se encontraba en parcial abandono ${ }^{15}$. Así, la muralla se utilizó para cerrar el frente norte del recinto fabril, como se muestra en la litografía de Francisco Javier Parcerisa, construyéndose en los otros tres lados un foso que protegía y aislaba el edificio (Figura 1) ${ }^{16}$. Este conjunto de reformas denotaban el interés por parte de las autoridades municipales en la mejora del sector, lo que unido a las casas adosadas a la muralla y al paso del Tagarete, constituía uno de los paisajes prototípicos del romanticismo sevillano reproducido en multitud de pinturas y dibujos. De entre ellos, el realizado por Richard Ford en 1830 y conservado en la colección Brinsley Ford de Londres, da buena cuenta de las construcciones domésticas pegadas al muro, las cuales repercutían en la conservación y eficacia del propio recinto amurallado (Figura 2$)^{17}$. No obstante, en la representación del entorno de la Puerta de Jerez realizada por George Vivian en 1838 dicho espacio of rece una visión diferente, con un paisaje animado por carros y personajes cubiertos con calañeses, apareciendo la muralla precedida por malezas y eneas nacientes en el arroyo Tagarete, lo que parece indicar el abandono de la zona aunque también pudiera tratarse de una visión fantaseada para ofrecer una imagen más en sintonía con la visión romántica (Figura 3). Menos conocida es la vista pintada por el capitán de ingenieros Juan Miguel Arrambide en 1825, en la cual la ordenación y limpieza del paisaje contrasta con el hacinamiento de la anterior representación (Figura 4).

${ }^{14}$ Véase BONET CORREA, Antonio; MIRANDA, Fátima y LORENZO, Soledad: La polémica ingenieros-arquitectos en España. Siglo XIX. Madrid, 1985.

${ }^{15}$ Dicho ingeniero también emitió un informe sobre el estado de las defensas de la ciudad, en concreto sobre la Torre del Oro, afectada tras el terremoto de 1755, habiendo sido recogido por FALCÓN MÁRQUEZ, Teodoro: La Torre del Oro. Sevilla, 1983, pp. 61-63. Sobre la reurbanización de la actual calle San Fernando, antigua de San Carlos, se conserva un plano firmado por Van der Borcht, fechado en 1760 y publicado por FALCÓN MÁRQUEZ, Teodoro: "La Fábrica de Tabacos", Aparejadores, 9, 1982, pp. 20-27.

16 SUÁREZ GARMENDIA, José Manuel: "La puerta Nueva o de San Fernando", Laboratorio de Arte, 2, 1989, p. 176.

${ }^{17}$ El principal catálogo que recoge la producción realizada por Richard Ford en Sevilla fue realizado por RODRÍGUEZ BARBERÁN, Javier: Richard Ford y Sevilla (18301833). Sevilla, 2007. 
El referido conjunto de reformas iniciadas durante el siglo XVIII no fueron al parecer suficientes para la consolidación del muro sur. De hecho, según las noticias ahora localizadas, la arriada producida por el desborde del Tagarete en la noche del día 6 de enero de 1830 provocó el hundimiento de un lienzo de muralla cercano a la Puerta de Jerez de algo más de 20 metros de ancho y unos 7 metros de alto, quedando otro fragmento de hasta 10 metros en peligro de derrumbe, lo que facilitaría el paso de las aguas al interior de la ciudad ${ }^{18}$. Ante tal adversidad y puesto que este sector pertenecía al Real Alcázar, José Domínguez Bécquer, administrador del Real Patrimonio, encargó al arquitecto Melchor Cano reconocer el sector dañado. Cano, quien ocupó diversos cargos durante su estancia hispalense, había sido nombrado director de las obras del Real Patrimonio por el rey Fernando VII, por lo que le correspondía la restauración de la muralla dañada, así como el mantenimiento del Alcázar y de todos los edificios dependientes, incluidos la Torre del Oro, la coracha que la unía al palacio y el tramo sur del recinto murario ${ }^{19}$.

Tras el citado encargo, Cano visitó la zona derruida una semana después del suceso, reconociendo que la causa del derrumbe se basaba tanto en la falta de revestimiento de la fábrica, producto del escaso interés por parte de las autoridades en su protección, como en la erosión generada por la fuerza del agua. Así, para evitar futuras inundaciones, el arquitecto propuso iniciar una serie de remodelaciones en la zona afectada, las cuales mejorarían la función de la muralla como barrera protectora ante las crecidas del arroyo y, por ende, del río. Los trabajos se iniciarían con la limpieza de los escombros y con la demolición de la parte ruinosa contigua a la hundida, ya que había sufrido desperfectos. A partir de ahí, se procedería a construir un nuevo lienzo de unos 33 metros de largo, con la misma profundidad y altura que el resto de la muralla. Para ello, Cano recomendó la utilización de cal y ladrillo, pues consideraba que estos materiales eran más resistentes al agua que el antiguo tapial. Igualmente, novedosa resultaría la apertura de una serie de huecos a lo largo del nuevo muro para facilitar el paso del agua, lo que reduciría la resistencia ante las crecidas y, en consecuencia, ralentizaría la erosión de la fábrica. En caso de aprobarse tal intervención, el arquitecto descartaba la utilización de otros mecanismos para contener las riadas, pues

18 ARAS (Archivo del Real Alcázar de Sevilla), caja 607, exp. 17, Reconocimiento del arquitecto Melchor Cano.

19 A pesar de que Melchor Cano ocupase los cargos de arquitecto mayor de la Ciudad, de su Real Consulado, del Cabildo Eclesiástico y Dignidad Arzobispal, no destacó por una producción arquitectónica demasiado amplia, siendo la remodelación del mercado de la Encarnación su obra de mayor trascendencia. Diferente fue su labor como urbanista, pues además del paseo de las Delicias, también proyectó las actuales plazas de la Magdalena y del Duque. SUÁREZ GARMENDIA, José Manuel: Arquitectura y urbanismo en Sevilla durante el siglo XIX. Sevilla, 1986, p. 49. 
consideraba que las murallas seguían siendo el método más barato para ello. Este pensamiento obedecía al ideal urbanístico que Cano había expresado en su discurso de ingreso a la Real Academia de Bellas Artes de San Fernando en 1822, al considerar que las murallas de cualquier ciudad dividían los espacios urbanos delimitando el centro de los arrabales, en los cuales se deberían construir los cementerios, lavaderos y otros inmuebles funcionales y de servicio ${ }^{20}$.

El reconocimiento y la propuesta de Melchor Cano fueron enviados a Francisco Blasco, administrador del Patrimonio del Real Alcázar de Sevilla, quien debía autorizar la obra. No obstante, el proyecto no se aceptó de inmediato, pues se localizaron en el archivo de la institución una serie de Reales Órdenes fechadas en 1504 y 1731, indicando que la financiación de este tipo de reparaciones debía hacerse con fondos municipales. Por ello, José Domínguez Bécquer requirió en julio de 1830 contactar con el Ayuntamiento para que verificase la ruina y deterioro de la muralla inmediata a la Puerta de Jerez, a fin de que procediese a su reparación, eximiendo al Alcázar de cualquier responsabilidad con respecto a los costos. Por otro lado, Domínguez exigió en su escrito recuperar los derechos patrimoniales usurpados tras la ocupación de parte de la coracha que unía el Alcázar con la Torre del Oro, al haber sido invadida por casas adosadas, alacenas y otras construcciones. Con ello, la administración del palacio obligaba al Ayuntamiento a dejar expedito este espacio, al no haber controlado el levantamiento de edificios en un terreno que era de propiedad real. Esta exigencia obedecía al plan de restablecimiento de la comunicación entre el Alcázar y la Torre del Oro que desde 1825 desarrollaba la administración real, que dio como resultado la elaboración de un presupuesto dos años después por Melchor Cano para la restitución del mencionado paso $^{21}$. Con ello, se insistía en un pleito entorno al pago del mantenimiento y restauración de las murallas del sector sur de la ciudad, ya que tanto la administración palaciega como la municipal intentaban eludir cualquier responsabilidad ante el problema suscitado.

De inmediato, el gobierno del asistente Arjona, conocedor de las Reales Órdenes comentadas y ante la necesidad de reparar las murallas, convino en reconocer la coracha, el número de casas adosadas y la posibilidad de rehabilitar la zona. Dicha labor volvería a recaer en el arquitecto Melchor Cano, quien tras haber proyectado la rehabilitación ya comentada de las murallas hundidas en la Puerta de Jerez, afrontaba esta nueva labor relacionada con el perímetro amurallado hispalense. En este caso, el arquitecto debía valorar los impedimentos existentes para liberar la coracha y cuantificar el número de fábricas anexadas que

${ }^{20}$ ANTIGÜEDAD DEL CASTILLO-OLIVARES, Ma Dolores: "El arquitecto Melchor Cano y la teoría de la ciudad", Espacio, tiempo y forma. Serie VII. Historia del Arte, 3, 1990, p. 419.

${ }^{21}$ ESPIAU EIZAGUIRRE, Mercedes: La Casa de la Moneda..., op. cit., p. 184. 
obstruían el tránsito entre el Alcázar y la Torre del Oro ${ }^{22}$. El proyecto se completaría con la construcción de un almacén rodeado por un malecón que contuviese las aguas durante las futuras crecidas del río. El arquitecto, continuando la línea estética impuesta por Vermondo Resta en las casas colindantes, empleó un lenguaje clásico en la articulación de la fachada del mencionado almacén, pues ésta se componía por dos cuerpos jalonados por pilastras y divididos por un entablamento y cornisa ${ }^{23}$. El edificio, considerado por Espiau como una de las primeras obras academicistas de la arquitectura sevillana, supuso la culminación del proyecto de reforma del sector sur de la muralla hispalense dirigido por Cano, quien no solo se limitó a rehabilitar lo dañado, sino que también incorporó nuevas fábricas a las ya existentes, empleando para ellas los esquemas y principios estéticos de su formación académica.

Dicha actuación debe encuadrase en la situación especial y en cierto punto conflictiva por cuestiones competenciales que se vivió en el ámbito de la arquitectura española en las décadas centrales del siglo XIX. La profunda implicación por parte del arquitecto Melchor Cano en la renovación del área citada obedece no solo a las necesidades de modernización del sector sur de la ciudad reclamada por las instituciones municipales, sino también a la obligación de abrir nuevos espacios en un entorno que se encontraba aprisionado por la acumulación de edificios y por la falta de mantenimiento de su muralla. Ciertamente, Cano respetó el trazado del muro al limitarse a restaurar lo dañado, demostrando su interés por las construcciones antiguas durante un periodo en el que esa actitud no era la predominante. Por otra parte, su intervención se debe relacionar con el cargo municipal que ocupaba, pues en principio, tras la fundación del Cuerpo de Ingenieros en 1711, no era competencia de un arquitecto ocuparse de tal menester. Además, tras surgir en 1803 la Escuela de Caminos y Canales se ahondaba en la especificidad de los trabajos afrontados por los ingenieros, quienes debían ocuparse de las reformas de infraestructuras como murallas, puentes o alcantarillas. En 1835 se creó el Cuerpo de Ingenieros Civiles, lo que reducía el número de competencias de los arquitectos y, finalmente, en 1844 se legisló que estos únicamente interviniesen en los edificios urbanos, prohibiéndoles actuar sobre caminos, canales, puertos o murallas. Es evidente que esta circunstancia reducía las posibilidades de intervención de los arquitectos en favor de los ingenieros, iniciándose una encendida disputa que se acrecentó cuando en 1845 se le confirió al Cuerpo de Ingenieros Civiles la dirección de todas las obras públicas del reino ${ }^{24}$.

${ }^{22}$ ARAS, caja 607, exp. 17, Para que el Excmo. Ayuntamiento de esta ciudad levante el lienzo de muralla de la inmediación de la Puerta de Jerez y restitución por los vecinos que existen en el terreno inmediato entre dicha muralla a la Torre del Oro del que han usurpado.

${ }^{23}$ ESPIAU EIZAGUIRRE, Mercedes: La Casa de la Moneda ..., op. cit., pp. 187-190.

${ }^{24}$ BONET CORREA, Antonio: "Razón e historia de un debate teórico-profesional”, en BONET CORREA, Antonio; MIRANDA, Fátima y LORENZO, Soledad: La 
Por tanto, al no surgir hasta fines del siglo XIX un cuerpo facultativo que respaldase los intereses económicos y sociales de los arquitectos, estos afrontaban cualquier trabajo acorde al cargo que ocupasen. El hecho de que los arquitectos interviniesen en murallas, caminos o puentes sin contar con la formación requerida para tales menesteres suscitó un debate al respecto. Entre otros, Agustín de Betancourt criticaba la falta de conocimiento de los arquitectos en matemáticas, cálculo y geometría, lo que les impedía reparar correctamente las murallas de las ciudades ${ }^{25}$. Distinta era la visión de arquitectos como Antonio de Zabaleta o Narciso Pascual y Colomer, quienes aceptaban la diferenciación entre las dos profesiones, si bien defendían que la arquitectura era el todo y la ingeniería solo una parte $^{26}$. En este sentido, los arquitectos se veían capaces de proyectar modificaciones en las defensas de la ciudad, en sus caminos o en sus puentes, mientras que los ingenieros se consideraban formados específicamente para dichas tareas.

Es en este contexto en el que Melchor Cano trabajó en las murallas de Sevilla tras haber recibido una formación academicista, como Zabaleta o Colomer, y cuyo pensamiento defendía la amplia preparación del arquitecto, lo que en absoluto les impedía trabajar en caminos, puentes o murallas. A pesar de que los trabajos desarrollados por Cano fuesen de restitución y limpieza de parte de la muralla, lo cierto es que al haberse constituido un cuerpo de ingenieros específico para tales asuntos era responsabilidad de estos dirigir tales trabajos. No obstante, el Ayuntamiento hispalense confió en su maestro mayor, quien no solo respetó el antiguo trazado de la muralla y la coracha, sino que también diseñó un nuevo edificio de acuerdo a los postulados academicistas conocidos durante su formación. Todo ello, permite ofrecer una nueva visión sobre un arquitecto parcialmente desconocido que, a pesar de no contar con una vasta producción, introdujo nuevos modelos arquitectónicos que dejaron su influencia en los maestros locales hispalenses.

Fecha de recepción: 15 de septiembre de 2017

Fecha de aceptación: 30 de enero de 2018

polémica ingenieros-arquitectos..., op. cit., pp. 31-33.

${ }^{25}$ BETANCOURT, Agustín: "Noticia del estado actual de los Caminos y Canales de España, causas de sus atrasos y defectos y medio de remediarlo en adelante", Revista de Obras Públicas, 6, 1869, p. 68.

${ }^{26}$ ZABALETA, Antonio y COLOMER, Narciso: "Arquitectura y obras públicas", Boletín Enciclopédico de Nobles Artes, 18, 1846, pp. 283-287. 


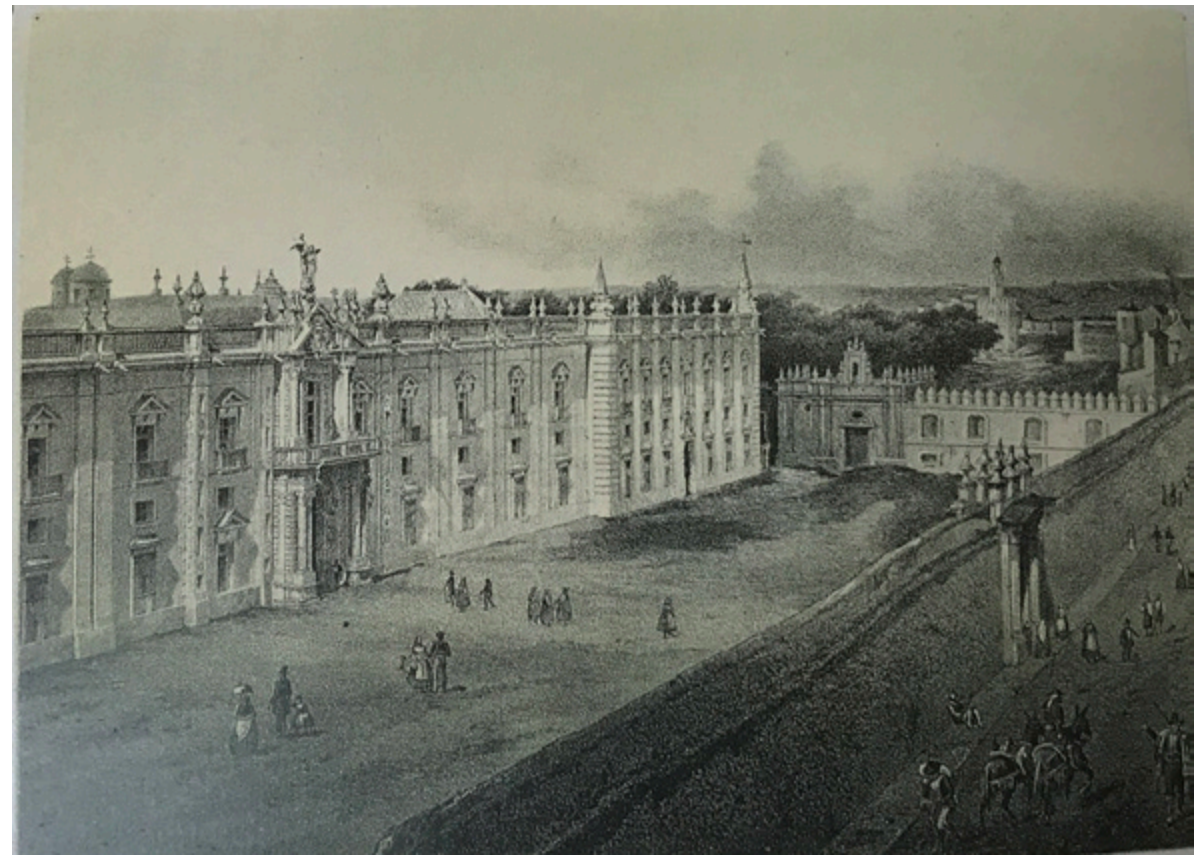

Figura 1. Francisco Javier Parcerisa, Fábrica de Tabacos, 1832, litografía, en DE MADRAZO, Pedro: Recuerdos y bellezas de España. Sevilla y Cádiz. Madrid, 1856. 


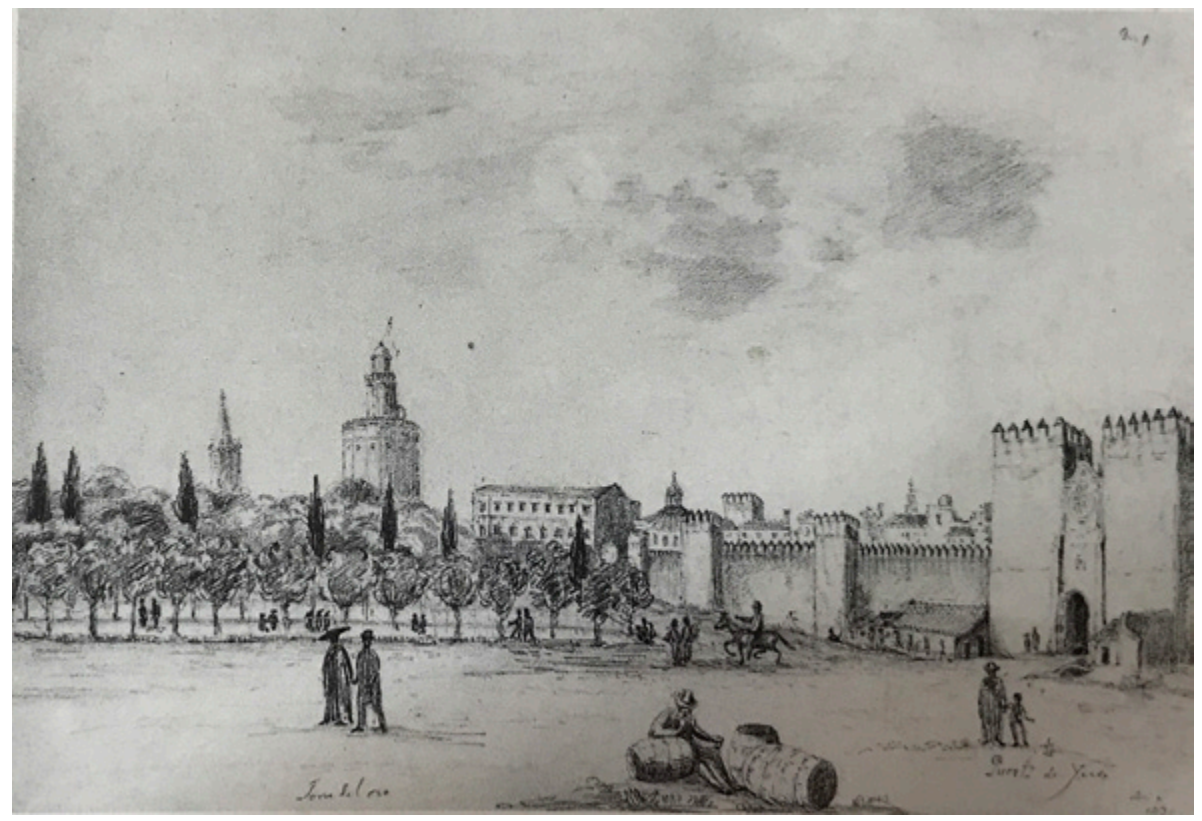

Figura 2. Richard Ford, Puerta de Jerez, 1830, dibujo a lápiz. 


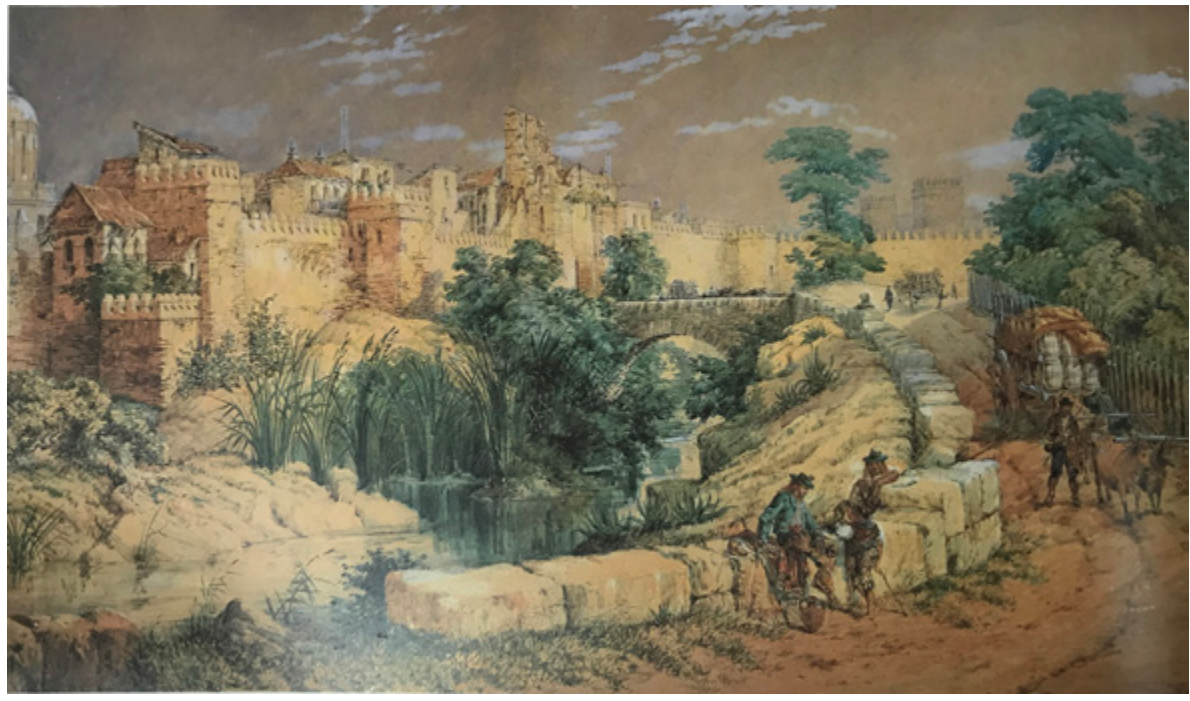

Figura 3. George Vivian, Puerta de Jerez, 1838, aguada.

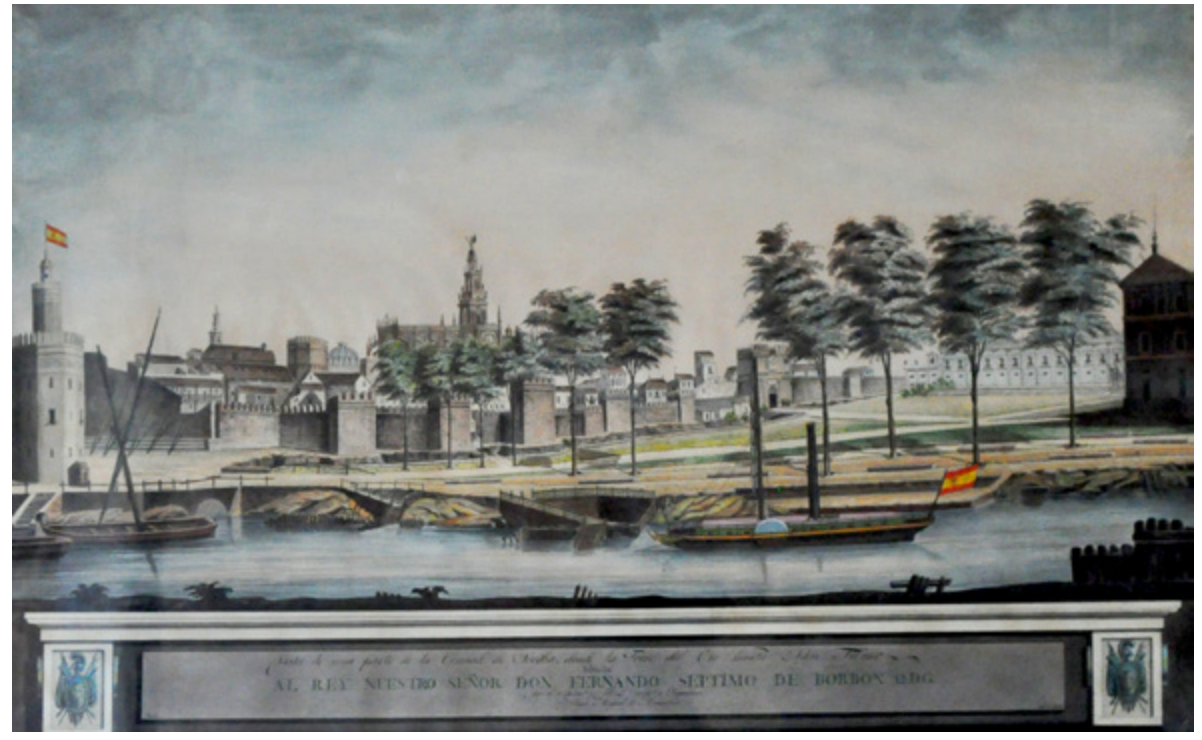

Figura 4. Juan Miguel Arrambide, Vista de Sevilla, 1825, acuarela. 